\title{
COMPORTAMENTO DO MARMELEIRO 'MENDOZA INTA-37' (1)
}

\author{
FERNANDO ANTONIO CAMPO DALL'ORTO $(2,5)$, \\ MÁRIO OJIMA $\left({ }^{2}\right)$, WILSON BARBOSA $\left({ }^{2,5}\right)$, \\ FERNANDO PICARELLI MARTINS $\left({ }^{3,5}\right)$ e ORLANDO RIGITANO $\left({ }^{4}\right)$
}

\begin{abstract}
RESUMO
Relatam-se observações e dados obtidos durante dez anos com o cultivar de marmelo Mendoza INTA-37, selecionado no Instituto Nacional de Tecnologia Agropecuária, Argentina, que apresentou excelente adaptação nas condições de inverno brando paulista. Os frutos são grandes, globosos e de belo aspecto. A polpa é clara, de consistência firme e textura meio grosseira; as lojas cartilaginosas são grandes e há pouca mucilagem envolvendo as sementes, relativamente pouco numerosas, cerca de 17 por fruto. A planta é de porte volumoso, vigorosa, produtiva e de baixa suscetibilidade à entomosporiose. O florescimento é um tanto tardio, porém os frutos amadurecem cedo, ao final de janeiro, nas condiçōes de Jundial, SP. Os frutos apresentam aptidão para fins industriais, pois, manufaturados experimentalmente, resultaram em marmelada semelhante àquelas obtidas de modo artesanal, com os cultivares Portugal ou Smyrna. Essas caracteristicas justificam a inclusāo do cultivar Mendoza INTA-37 nos pomares comerciais em São Paulo, e no programa de melhoramento varietal do marmeleiro, do Instituto Agronômico.
\end{abstract}

Termos de indexação: marmeleiro, Cydonia oblonga Mill., 'Mendoza INTA-37', frutificação, marmelada ou doce em pasta.

(1) Recebido para publicação em 30 de outubro de 1985.

(2) Seção de Fruticultura de Clima Temperado, Instituto Agronómico (IAC), Caixa Postal 28, 13001 Campinas (SP).

(3) Estação Experimental de Jundial, IAC.

$\left({ }^{4}\right)$ Instituto Agronómico (IAC).

$\left({ }^{5}\right)$ Com bolsa de suplementaçăo do CNPq. 


\section{INTRODUÇÃO}

No mundo antigo e no Brasil Colônia, poucos frutos como os do marmeleiro tiveram tão relevante papel. Atualmente, é dificil encontrar uma frutífera com seu valor histórico-social tāo pouco difundida e estudada. Apesar dessa relativa estagnação, a cultura do marmeleiro antecedeu em importância económica ao café, constituindo o primeiro produto de exportação paulista, ainda nos tempos coloniais (DALL'ORTO, 1982).

O marmeleiro (Cydonia oblonga Mill.) é uma frutffera perene da família das Rosáceas, de aptidão climática temperada e exigente de tratos culturais, mormente os fitossanitários. Adapta-se melhor aos solos orgânicos e requer um combate rígido à entomosporiose, doença fúngica que limita o seu cultivo. $O$ plantio é feito por estacas enraizadas das variedades a explorar, que, de modo genérico, são exigentes de polinização cruzada. Os frutos raramente são consumidos "in natura", sendo quase sempre industrializados para a produção de marmelada. O marmelo pode ser ainda utilizado em geléias, compotas, sopas, licores, xaropes e em finos pratos salgados. Sua pectina também pode ser empregada em farmácia e perfumaria. Ultimamente, tem-se dado bastante ênfase ao uso do marmeleiro como porta-enxerto de pereiras e nespereiras, a fim de provocar 0 ananismo das variedades copas, permitindo maior adensamento dos pomares (DALL'ORTO, 1982)

Nos últimos anos, a diminuigãa de oferta dessa matéria-prima vem sendo sentida pelas próprias indústrias, que a têm importado ou substituído em parte por maçã ou laranja. Em conseqüência, existem novamente estímulos à produçāo comercial econômica de marmelos, através de maior racionalização da cultura, incluindo a disponibilidade de cultivares opcionais, altamente promissores.

Nesse particular, dentro do seu programa de melhoramento genético do marmeleiro, a Seção de Fruticultura de Clima Temperado do Instituto Agronômico vem conduzindo campos experimentais, instalados principalmente na Estação Experimental de Jundial e de Tietê, no sentido de pesquisar o comportamento de material introduzido de várias procedências e efetuar seleção para obtenção de novos cultivares. A finalidade básica do trabalho é selecionar marmeleiros bem adaptados às condiçōes de inverno brando, com características agronómicas superiores, a saber. alta produtividade de frutos de boa qualidade para a indústria e para consumo "in natura", frutificação e maturação precoces, rusticidade das plantas e resistência ao agente causal da entomosporiose. Procura-se, também, a compatibilidade do material, para utilização do marmeleiro como porta-enxerto de pereira e nespereira.

Como resultado desse trabalho de melhoramento, foi apresentado recentemente o cultivar Provence, que, em virtude de boa produtividade de frutos adequados à industrialização, é apontado como bastante promissor à exploração comercial (DALL'ORTO et al., 1985). 
No entanto, é ainda restrito o número de cultivares disponíveis à marmelicultura em São Paulo e Estados vizinhos, onde predomina atualmente o chamado 'Portugal', seguido de 'Smyrna', de características que muito se assemelham. Nessas condiçōes, toma-se oportuno o lançamento de um novo cultivar de marmelo que reúna as características agronômicas desejadas, capaz, inclusive, de proporcionar a ampliação do perfodo de safra. Esses requisitos são preenchidos pelas características particulares do marmeleiro 'Mendoza INTA-37', cuja apresentação constitui o objetivo principal deste trabalho.

\section{MATERIAL E MÉTODOS}

\subsection{Origem do material}

Procedentes do Instituto Nacional de Tecnologia Agropecuária, Mendoza, Argentina, foram introduzidas no Instituto Agronômico, em 1970, borbulhas de três marmeleiros selecionados naquele País, para a produção precoce de frutos com qualidade superior e aptidāo para fins industriais, de florada tardia e épocas distintas de maturação. Esses materiais, enviados ao Instituto Agronômico por E.C.M. Pereira, da firma AGROCICA, Jundial, compreendiam os cultivares Mendoza INTA-37, 117 e 147, lançados ao cultivo comercial na Argentina, em 1969, após quinze anos de trabalho de melhoramento varietal desenvolvido com 0 marmeleiro, a partir de sementes de polinização livre do 'Smyma' (ROBY, 1969).

\subsection{Observações fitotécnicas}

Logo após o recebimento do material, procedeu-se a sua enxertia, em março de 1970, sobre marmeleiros 'Portugal', estabelecidos na colegão de germoplasma, em setembro do ano anterior, na Estação Experimental de Jundial. Para cada cultivar introduzido, destinaram-se três plantas, efetuando-se de três a seis enxertos de borbulhia, por planta. A área ocupada por planta depois de estabelecida era de $15 \mathrm{~m}^{2}$.

Houve bom pegamento dos enxertos, que inicialmente se desenvolveram com vegetação exuberante. As plantas receberam, todos os anos, os tratamentos convencionais necessários à cultura: podas de inverno e de verão, pulverizaçōes fitossanitárias, adubaçōes, cobertura morta e cultivo do solo (CAMPrNAS, 1980).

No ano agricola de 1975/76, nas plantas sobreenxertadas, constataramse pequenas produçōes iniciais apenas no 'Mendoza INTA-37'. Nos anos subseqüentes, esse cultivar apresentou sempre produçōes crescentes e maiores do que as dos outros marmeleiros. A partir de 1975/76, e por dez anos consecutivos, controlou-se a produtividade dos marmeleiros em estudo, junto aos demais da coleção de variedades, anotando-se o número e o peso dos frutos colhidos, bem 
como as respectivas épocas de maturação. Efetuou-se ainda a avaliação das características de comportamento vegetativo, florifero, frutífero e de resistência à entomosporiose, em protocolos sistemáticos, com atribuição de notas no campo, por dois observadores. A produçāo do cultivar Mendoza INTA-147, entretanto, não foi considerada, devido ao enfraquecimento gradual apresentado por suas plantas, no decorrer da experimentação.

Com os frutos dos cultivares Mendoza INTA-37, Portugal e Smyma, colhidos na última safra de controle (1984/85) na Estação Experimental de Jundial, junto aos frutos dos cultivares Portugal e Provence, da mesma safra, procedentes da Estação Experimental de Tietê, foi providenciada a manufatura experimental das respectivas marmeladas, numa indústria artesanal em Tietê, para testes de comparação de aptidão industrial. Em seguida, esses doces em pasta foram avaliados quanto ao aspecto, textura e sabor, por cinco provadores.

\section{RESULTADOS E DISCUSSÃO}

\subsection{Produtividade}

No quadro 1, são apresentadas as produçōes médias, por planta, em número e peso dos frutos, e o peso médio de um fruto, do marmeleiro Mendoza INTA-37, em dez anos consecutivos de controle - safras de 1975/76 a 1984/85.

QUADRO 1. Comportamento do marmeleiro 'Mendoza INTA-37' nas condiçōes da Estação Experimental de Jundial. Produçăo média das plantas, avaliada pelo número e peso dos frutos, por dez safras (1975/76 a 1984/86)

\begin{tabular}{|c|c|c|c|}
\hline \multirow[t]{2}{*}{ Safra } & \multicolumn{2}{|c|}{ Produção por planta } & \multirow{2}{*}{ Peso de um fruto } \\
\hline & $n^{0}$ & $\mathrm{~kg}$ & \\
\hline $1975 / 76 \ldots \ldots$ & 20 & 2,4 & 120 \\
\hline $1976 / 77 \ldots \ldots$ & 45 & 5,8 & 130 \\
\hline $1977 / 78 \ldots \ldots$ & 70 & 10,7 & 154 \\
\hline $1978 / 79 \ldots \ldots$ & 84 & 14,5 & 172 \\
\hline $1979 / 80 \ldots \ldots$ & 99 & 15,8 & 160 \\
\hline $1980 / 81 \ldots \ldots$ & 90 & 9,9 & 110 \\
\hline $1981 / 82 \ldots \ldots$ & 132 & 14,0 & 106 \\
\hline $1982 / 83 \ldots \ldots \ldots$ & 136 & 16,3 & 120 \\
\hline $1983 / 84 \ldots \ldots$ & 147 & 16,8 & 114 \\
\hline $1984 / 85 \ldots \ldots$ & 162 & 21,0 & 130 \\
\hline
\end{tabular}


Como se observa, o cultivar Mendoza INTA-37 apresentou produçōes bastante expressivas e crescentes, nos anos de acompanhamento experimental. A colheita média anual por planta, nos últimos cinco anos, quando as plantas se aproximavam da fase adulta, foi de 133 frutos pesando 15,6kg. Essa média pode ser considerada das mais auspiciosas, uma vez que as plantas contíguas do cv.Portugal, o mais difundido nas condiçōes brasileiras, e o segundo mais produtivo do lote experimental, tiveram, no mesmo perfodo, uma produção de 125 frutos pesando $11,0 \mathrm{~kg}$ por planta, por ano. O cultivar Mendoza INTA-117, por sua vez, produziu, ainda nos últimos cinco anos, uma média de $8,0 \mathrm{~kg}$ de marmelos por planta, por ano. Outros marmeleiros tiveram médias ainda mais baixas de produção, que se alternava nas diversas safras consideradas, demonstrando indesejável irregularidade produtiva.

\subsection{Descrição do material}

'Mendoza INTA-37' apresenta frutos grandes, globosos, de belo aspecto (integros e bem desenvolvidos, podendo atingir até $300 \mathrm{~g}$ ), base peduncular larga e cavidade rasa, ápice calicinal com bordos salientes e cavidade pouco profunda. Película de pouca pubescência, lisa e de coloração amarelada; polpa clara, bastante espessa, de consistência firme e textura um tanto grosseira. Sabor doceacidulado; aroma pronunciado. Sementes em número relativamente pequeno - 15 a 20 - em cinco lojas cartilaginosas grandes, praticamente desprovidas de mucilagem. Planta vigorosa, frondosa, de porte volumoso e dotada de ramos com boa distribuiçāo lateral, abrindo-se naturalmente com o peso dos frutos. Numerosos ramos frutíferos de comprimento médio, bem enfolhados e de coloração castanha. Folhas de tamanho médio a grande, ovaladas, pouco pontiagudas, verde-escuras e de baixa suscetibilidade à entomosporiose, em confronto com as outras variedades observadas. Flores abundantes, rosadas, e anteras com polínio amarelo, atraentes. Em testes laboratoriais, constataram-se em média 19 anteras por flor e cerca de oito mil grãos de pólen por antera, com capacidade germinativa de $60,6 \%$. Florescimento um tanto tardio em relação às outras variedades, porém a maturação dos frutos até vinte dias mais precoce.

\subsection{Teste de utilização industrial}

O teste de utilização do marmelo 'Mendoza INTA-37' para fins industriais demonstrou que ele possui teores adequados de pectina e de acidez à manufatura da marmelada, dadas as qualidades do produto final. A marmelada apresenta coloração vermelho-escura, de maior consistência que a elaborada com os marmelos 'Portugal' e 'Smyma', caracterizando-se também por sua textura de granulação um pouco mais grosseira. Dentre o material testado, o 'Provence' continuou a destacar-se pela textura de granulação mais fina e delicada, confirmando resultados anteriores (DAL'L'ORTO et al., 1985). 
Em testes de degustação, a marmelada do 'Mendoza INTA-37' não obteve a preferência dos provadores, porém todos foram unânimes em concordar que esse marmelo propicia um produto perfeitamente viável para fins comerciais. Constatou-se também que a referida marmelada apresenta caracteristicas peculiares que lembram mais aquelas de manufatura artesanal, oriundas das antigas indústrias de doces (Fig. 1).

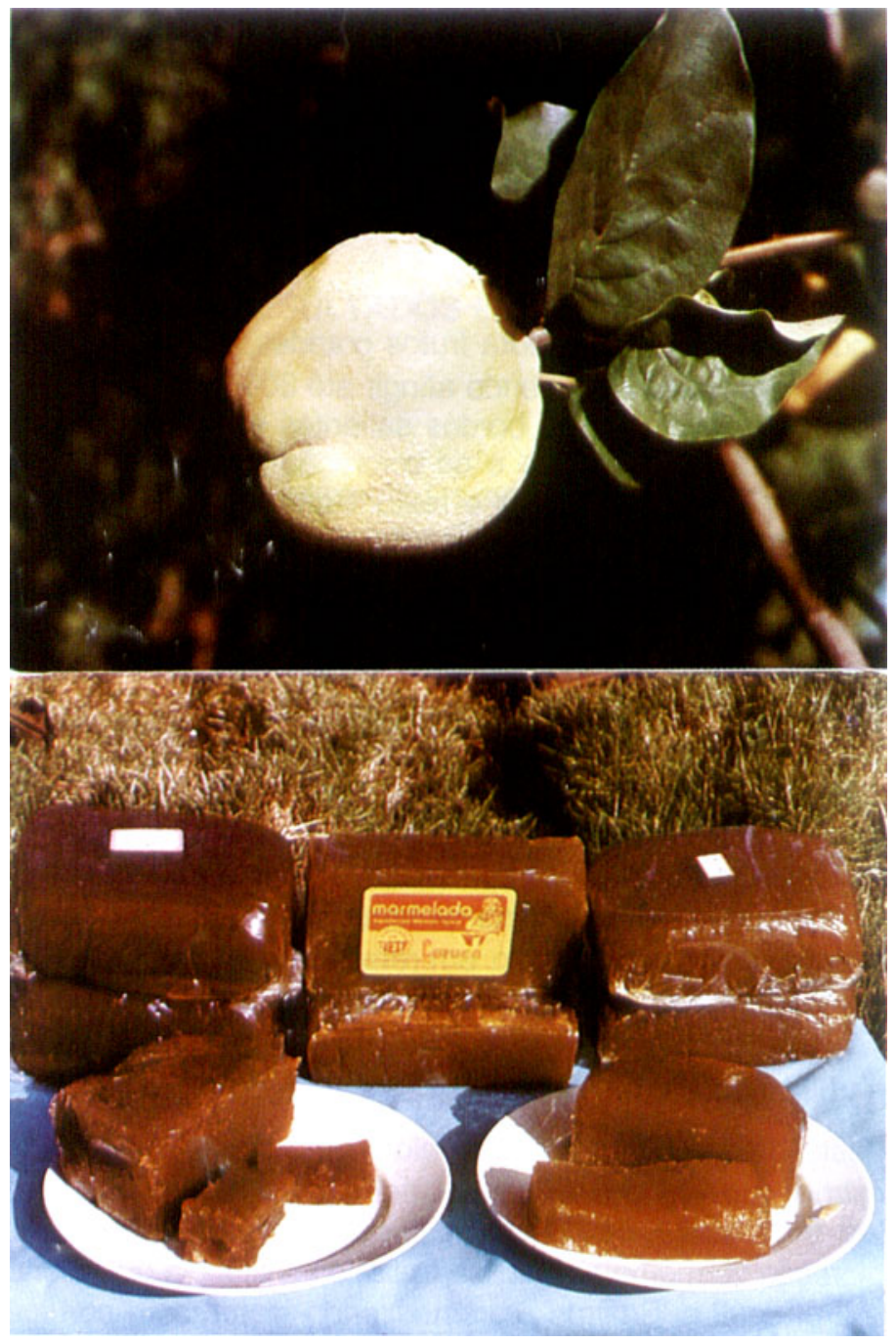

FIGURA 1. Doces em pasta dos marmelos 'Mendoza INTA-37' e 'Provence', confeccionados por indústria artesanal em Tietê, SP. 


\subsection{Perspectivas agronômicas}

A excelente adaptabilidade do marmeleiro 'Mendoza INTA-37 nas condições de Jundial, SP, foi demonstrada por sua produtividade. As plantas apresentaram-se com vegetação exuberante e baixa suscetibilidade à entomosporiose. Além disso, o tamanho e a beleza de seus frutos, com teores de pectina e de acidez adequados à produção de marmelada industrial, constituem méritos suficientes para indicá-lo como nova opgäo varietal, no restabelecimento da cultura do marmeleiro em São Paulo. Por outro lado, suas caracteristicas de florescimento tardio e maturação precoce dos frutos recomendam-no ao plantio em regiőes sujeitas a geadas tardias, ao mesmo tempo que o indicam como material opcional de valor à própria dilatação do período de safra dos cultivares de marmelo atualmente disponiveis.

Tais caracteristicas vêm sendo intensamente aproveitadas no programa de melhoramento genético do IAC (DALL'ORTO, 1982), tendo-se em vista que esse cultivar produz sementes graúdas, de fácil manejo, portanto, e com excelente poder germinativo, sendo elevado o rendimento de "seedlings" aproveitáveis, oriundos de polinizaçāo livre. Acresce-se quie quanto a seu uso como porta-enxerto ananicante, são promissores os resultados obtidos até o momento, demonstrando sua viabilidade especialmente para pereiras e nespereiras.

\section{CONCLUSŌES}

1) O cultivar Mendoza INTA-37, avaliado nas condiçöes de Jundial, SP, mostrou-se altamente promissor para constituir nova opção varietal à marmelicultura paulista, por suas qualidades agronômicas positivas: planta vigorosa, baixa suscetibilidade à entomosporiose, alta produtividade de frutos graúdos, de belo aspecto e adequados à confecção de marmelada.

2) Por outro lado, as informações que vêm sendo colhidas, durante a execução dos trabalhos de melhoramento genético do marmeleiro, sugerem ser ele um progenitor dos mais apropriados para obtenção de descendentes de valor, tanto para produção de frutos quanto para uso como porta-enxerto ananicante de pereira e nespereira.

\section{SUMMARY}

\section{BEHAVIOR OF MENDOZA INTA-37 QUINCE CULTIVAR}

Mendoza INTA-37 is a quince cultivar released by INTA in Argentina in 1969, and introduced in the State of São Paulo, Brazil, through AGROCICA, Jundial, State of Sāo Paulo, in 1970. Its agronomic behavior 
was observed at the instituto Agronômico of Campinas with respect to the adaptation to the mild winter of State of São Paulo. Mendoza INTA-37 presents vigorous trees and high fruit productivity. The fruits are big, of beautiful appearence and early ripening, showing to be an excellent raw material for industrialization as jam of high quality. These characteristics justify its inclusion in commercial orchards in São Paulo and in the quince breeding program of the Instituto Agronômico.

Index terms: quince, Cydonia oblonga Mill., 'Mendoza INTA-37', productivity, jam.

\section{AGRADECIMENTOS}

Os autores agradecem ao Eng--Agro Eurico C.M. Pereira, da Companhia Industrial de Conservas Alimentícias (CICA), Jundiaí, SP, a cessão do material de propagação, e à Sra. Maria Casagrande, proprietária de indústria artesanal, em Tietê, SP, a confecção experimental das marmeladas analisadas.

\section{REFERÊNCIAS BIBLIOGRÁFICAS}

CAMPINAS. Instituto Agronômico. Instruçōes agrícolas para o Estado de Sāo Paulo. 2.ed. rev. atual. Campinas, 1980. 273p. (Boletim, 200)

DALL'ORTO, F.A.C. Marmeleiro (Cydonia oblonga Mill.) - propagação seminffera, citogenética e radiossensitividade - bases ao melhorarnento genético e à obtenção de porta-enxertos. Piracicaba, ESALQ/USP, 1982. 161p. Dissertação (Mestrado)

_- OJIMA, M.; BARBOSA, W.; RIGITANO, O.; SABINO, J.C. \& VEIGA, A.A. Frutificação do marmeleiro 'Provence'. Bragantia, Campinas, 44(1):509-514, 1985.

ROBY, F. Tres nuevas variedades de membrilleros creados en Mendoza. Oeste: Revista de la Bolsa de Comercio de Mendoza, Mendoza, 28/29:81-85, 1969. 